\title{
Vacuolar myopathy with sarcoplasmic reticulum protein aggregates
}

INSERM

\section{Source}

INSERM. (1999). Orphanet: an online rare disease and orphan drug data base. Vacuolar myopathy with sarcoplasmic reticulum protein aggregates. ORPHA:88635

Myopathy due to calsequestrin and SERCA1 protein overload is characterised by mild myopathy or elevated levels of creatine kinase in the blood without associated symptoms. 